\title{
Pengaruh Model Learning Cycle 5E Terhadap Motivasi Belajar dan Hasil Belajar Fisika Peserta Didik SMA Negeri 2 Woha Bima
}

\author{
Muhammad Fuadi ${ }^{1)}$, Muhammad Arsyad ${ }^{2)}$, Kaharuddin Arafah ${ }^{2)}$, Asriyadin ${ }^{1),}$ \\ ${ }^{1)}$ STKIP Taman Siswa Bima \\ ${ }^{2)}$ Universitas Negeri Makassar \\ *asriyadin@gmail.com
}

Abstrak: Penelitian ini adalah penelitian kuantitatif menggunakan The Randomized Postest-Only Control Group Design, yang bertujuan untuk menganalisis perbedaan hasil belajar fisika antara peserta didik yang diajar menggunakan model learning cycle 5E dengan model konvensional pada peserta didik. Penelitian ini dilakukan pada siswa kelas XI IPA SMAN 2 Bima. Hasil analisis deskriptif memperlihatkan bahwa skor rata-rata motivasi belajar fisika peserta didik yang diajar menggunakan model learning cycle 5E sebesar 120.48 dan standar deviasi 6,178 dan skor rata-rata hasil belajar peserta didik yang diajar menggunakan model learning cycle 5E sebesar 21,90 dan standar deviasi 3,59. Sedangkan skor rata-rata motivasi belajar fisika peserta didik yang diajar secara konvensional 116,38 dan standar deviasi 5.696 dan skor rata-rata hasil belajar peserta didik yang diajar menggunakan metode konvensional 18,90 dan standar deviasi 3,93. Analisis inferensial menggunakan uji-t dua pihak dengan taraf signifikan $\alpha=0,05$ dengan kesimpulan bahwa 1) Terdapat perbedaan Motivasi belajar fisika yang signifikan antara yang diajar menggunakan model pembelajaran learning cycle 5E dengan model konvensional peserta didik pada kelas XI IPA SMAN 2 Bima; 2) Terdapat perbedaan hasil belajar fisika yang signifikan antara yang diajar menggunakan model pembelajaran learning cycle 5E dengan model konvensional peserta didik pada kelas XI IPA SMAN 2 Bima.

Kata Kunci: Model Learning cycle 5E, Konversional, Motivasi, Hasil Belajar

\section{Pendahuluan}

Salah satu cabang IPA adalah fisika. Fisika merupakan salah satu mata pelajaran mencakup materi serta perhitungan yang bagi sebagian besar peserta didik dirasa sulit dipahami (Nisa' 2014; Passon, Zügge, and GrebeEllis 2019). Seorang guru dituntut memacu peserta didik agar tertarik dalam tiap materi fisika yang diajarkan sehingga peserta didik dapat mengikuti tiap materi serta berpartisipasi aktif dalam pembelajaran. Oleh karena itu, untuk meningkatkan kompetensi sebagai guru fisika, seorang guru harus meningkatkan kemampuan mengajar yaitu membangun komunikasi yang baik dengan peserta didik agar peserta didik tidak merasa takut dengan guru sehingga dapat lebih mudah membantu peserta didik belajar karena merasa diterima oleh guru. Selanjutnya guru perlu mengembangkan model pembelajaran agar dalam hal mengajar lebih bervariatif sehingga peserta didik tidak merasa bosan dan terus dipacu agar pandangan dan pemikiran terhadap fisika semakin berkembang

Berdasarkan hasil wawancara dengan guru mata pelajaran fisika di kelas XI SMAN 2 Woha Bima, menunjukan beberapa permasalahan yang dialami pada saat proses pembelajaran berlangsung yaitu : 1) peserta didik pada umumnya tidak semua bertanya, hanya dua atau tiga orang, 2) peserta didik yang menjawab pertanyaan hanya beberapa orang sekitar satu atau dua orang, 3) peserta didik yang mengerjakan soal latihan hanya sebanyak tujuh sampai sepuluh orang. Analisis hasil ulangan yang dilakukan guru fisika selalu menunjukkan indikasi bahwa hampir mencapai $50 \%$ peserta didik mendapatkan nilai ketuntasan belajar minimal (KBM) yautu 75 dari skala 100, sehingga peserta didik yang belum mencapai ketuntasan belajar minimal 
(KBM) harus mengikuti remedial. Kendala tersebut dapat diatasi dengan Sehingga diperlukan suatu model pembelajaran yang lebih efektif yaitu membuat siswa mampu mengeskplor kemampuan yang dimilikinya. Kendala tersebut dapat di atasi dengan menggunakan model pembelajaran siklus belajar 5E (Learning cycle).

Learning cycle 5 fase lebih dikenal dengan Learning cycle "5E". Fase-fase yang terdapat dalam model pembelajaran Learning cycle "5E", yaitu: Engagement, Exploration, Explaination, Elaboration, Menerapkan model pembelajaran learning cycle 5E ini, diharapkan peserta didik tidak hanya mendengar keterangan dari guru tetapi dapat berperan aktif untuk menggali, menganalisis, mengevaluasi pemahamannya terhadap konsep yang dipelajari. Pembelajaran dengan model learning cycle ini, diharapkan peserta didik tidak hanya mendengar keterangan dari guru tetapi dapat berperan aktif untuk menggali, menganalisis, mengevaluasi pemahamannya terhadap konsep yang dipelajar.

Pembelajaran dengan model learning cycle 5E ini juga mampu menciptakan pembelajaran menyenangkan bagi peserta didik (Pratiwi \& Supardi, 2014), karena peserta didik dilibatkan secara langsung dalam proses pembelajaran dan diberikan kesempatan sepenuhnya dalam mengemukakan ide-ide yang ada dalam pikirannya. Kondisi menyenangkan saat kegiatan pembelajaran berlangsung akan memotivasi peserta didik untuk belajar fisika lebih optimal dan mampu meningkatkan hasil belajar peserta didik.

Motivasi belajar yaitu daya dalam pribadi yang mendorong peserta didik untuk mempelajari sesuatu, yang dapat berasal dari dirinya sendiri (motivasi intrinsik), dan juga dari lingkungan sekitarnya (motivasi ekstrinsik). Menurut Nyoman \& Indra menjelaskan bahwa motivasi belajar merupakan keseluruhan daya penggerak didalam diri peserta didik yang menimbulkan kegiatan belajar, yang menjamin kelangsungan dari kegiatan belajar dan yang memberikan arah pada kegiatan belajar, sehingga tujuan yang dikehendaki dapat tercapai (Nyoman \& Indra, 2019).

Peningkatan motivasi yang terjadi pada peserta didik akan meningkatkan pula hasil belajar peserta didik itu sendiri, dimana hasil belajar adalah perubahan yang terjadi dalam individu karena usaha belajar (Halim, 2012). Sedangkan menurut (Nana Sudjana 2005) Hasil belajar peserta didik pada hakikatnya adalah perubahan mencakup bidang kognitif, afektif dan psikomotoris yang berorientasi pada proses belajar mengajar yang dialami peserta didik.

Penggunaan model pembelajaran learning cycle 5E dapat menjadikan siswa lebih aktif dalam pembelajaran (Sari and Kurniawati 2019; Senturk and Camliyer 2016; Suwito et al. 2020), karena terdapat proses integrasi dari pengetahuan baru dengan pengetahuan yang sudah dimiliki siswa sebelumnya. Pembelajaran dengan model learning cycle 5E ini juga mampu menciptakan pembelajaran menyenangkan bagi peserta didik (Aditya et al. 2019; Hasan and Nurhayati 2019), karena peserta didik dilibatkan secara langsung dalam proses pembelajaran dan diberikan kesempatan sepenuhnya dalam mengemukakan ide-ide yang ada dalam pikirannya. Berdasarkan penelitian yang dilakukan oleh Asriyadin, dkk dengan desain penelitian The Randomized Postest-Only Control Group Design menyimpulkan bahwa model siklus belajar 5E dapat mempengaruhi hasil belajar peserta didik (Asriyadin, Yus'iran, and Hafidah Nurul Fikri 2016). Hal ini didukung oleh penelitian Isnani, dkk degan desain penelitian Post-Test Only Control Group Design menunjukkan bahwa penerapan model Learning cycle 5E berperharuh signifikan terhadap hasil belajar pada ranah kognitif peserta didik (Isnani, Indrawati, and Subiki 2018).

Tujuan penelitian ini adalah untuk mendeskripsikan besar motivasi belajar peserta didik yang diajar menggunakan model learning cycle 5E pada kelas XI SMA Negeri 2 Woha Bima; untuk mendeskripsikan besar motivasi belajar peserta didik yang diajar menggunakan model konvensional (Direct intruction) pada kelas XI SMA Negeri 2 Woha Bima; untuk mendeskripsikan besar hasil belajar peserta didik yang diajar menggunakan model learning cycle 5E pada kelas XI SMA 2 Woha Bima; dan untuk mendeskripsikan besar hasil belajar peserta didik yang diajar menggunakan model konvensional (Direct intruction) pada kelas XI SMA Negeri 2 Woha Bima.

\section{Metode}

Penelitian ini menggunakan desain penelitian The Randomized Postest-Only Control Group Design. Rancangan ini terdiri atas dua kelompok yang setelah dilakukan penelitian kedua kelompok tersebut diberikan tes akhir (Postest) (Fraenkel, Wallen, and Hyun 2011). 
Dalam penelitian ini sample diambil secara cluster random sampling, yaitu acak kelas dari empat kelas yang menjadi anggota populasi penelitian. Untuk menentukan kelas eksperimen dan kelas kontrol.

Teknik pengumpulan data penelitian ini dilakukan dengan memberikan tes kepada pesta didik perlakuan untuk mengukur motivasi belajar dan hasil belajar fisika peserta didik. Instrumen motivasi belajar disusun dalam bentuk kuisioner yang juga telah divalidasi oleh pakar dan validasi empirik dari 40 butir soal yang dinyatakan valid oleh pakar. Pernyataan pada kuesioner ini terdiri atas pernyataan positif dan negatif. Format pilihan jawaban didasarkan pada skala model Likert yang terdiri atas 5 (lima) pilihan yang memuat alternatif pilihan jawaban: Sangat Tidak Sesuai (STS); Tidak Sesuai (TS); Kurang Sesuai (KS); Sesuai (S); dan Sangat Sesuai (SS).

\section{Hasil dan Pembahasan}

\section{Analisis Deskriptif}

Deskripsi Data Penelitian Motivasi Belajar

Untuk hasil analisis deskriptif terhadap motivasi belajar fisika pada peserta didik kelas eksperimen dan kelas kontrol dapat dilihat pada Tabel 1.

Tabel 1. Deskripsi Skor Motivasi Belajar Fisika Peserta Didik pada Kelas Eksperimen dan Kelas Kontrol

\begin{tabular}{cccc}
\hline & Motivasi_Kontrol & Motivasi_Eksperimen & Valid N \\
\hline $\mathrm{N}$ & 21 & 21 & 21 \\
Range & 18 & 23 & \\
Minimum & 106 & 108 & \\
Maximum & 124 & 131 & \\
Mean & 116.38 & 120.48 & \\
Std. Deviation & 5.696 & 6.178 & \\
Variance & 32.448 & 38.162 & \\
\hline
\end{tabular}

Sumber: Data Primer Terolah (2019)

Deskripsi Data Penelitian Hasil Belajar

Hasil analisi data deskriktif tes hasil belajar peserta didik pada kelas kontrol dan kelas Eksperimen dapat dilihat pada Tabel 2:

Tabel 2. Rangkuman Deskripsi Skor Hasil Belajar Fisika Peserta Didik pada Kelas Eksperimen dan Kelas Kontrol

\begin{tabular}{cccc}
\hline & Hasil Belajar Fisika Kelas Kontrol & Hasil Belajar Fisika Kelas Eksperimen & Valid N \\
\hline $\mathrm{N}$ & 21 & 21 & 21 \\
Range & 13 & 13 & \\
Minimum & 13 & 14 & \\
Maximum & 26 & 27 \\
Mean & 18,90 & 21,90 \\
Std. Deviation & 3,936 & 3,590 \\
Variance & 15,490 & 12,890 \\
\hline
\end{tabular}

(Sumber: Data Primer Terolah 2019)

\section{Analisis Inferensial}

Hasil uji hipotesis dengan analisis independent t-test dapat ditunjukkan pada Tabel 3.

Banyak hal yang dapat mempengaruhi hasil belajar. Salah satunya adalah motivasi belajar. Motivasi belajar siswa dapat ditingkatkan apabila gaya belajar siswa sesuai dengan model yang diterapkan oleh pendidik (Sum et al. 2020). Siswa yang memiliki motivasi rendah disebabkan karena pembelajaran yang tidak mendukung, dan begitu pula sebaliknya siswa yang memiliki motivasi belajar tinggi, karena model pembelajaran yang diterapkan mampu membuat siswa lebih tertarik untuk belajar, sehingga hasil belajar pun dapat meningkat. Penelitian ini bertujuan untuk menguji efektifitas dari model learning cycle 5E terhadap motivasi belajar dan hasil belajar. 
Sintaks model Learning Cycle 5E adalah Engagement (pembangkit minat), Exploration (menyelidiki), Explanation (penjelasan), Elaboration (pengembangan) dan Evaluation (evaluasi). Berdasarkan tahapan-tahapan pembelajaran tersebut, ketika tahapan engagement, guru berusaha memberikan pertanyaan-pertanyaan yang mampu membuat siswa tertantang untuk berpikir dan tertarik untuk menjawab. Kemudian tahap selanjutnya adalah meneyelidiki untuk mendapatkan jawaban tersebut, diikuti penjelasan dan pengembangan dan diakhiri tahap evaluasi. Pada tahap evaluasi, guru mengevaluasi apakah yang dilakukan oleh siswa untuk mendapatkan jawaban dari pertanyaan di awal telah sesuai dengan konsep sebenarnya.

Tabel 3. Rangkuman Hasil Analisis Uji Dua Pihak Independen t-tes.

\begin{tabular}{cccccc}
\hline \multirow{2}{*}{ Independen t-tes } & & \multicolumn{2}{c}{ Motivasi Belajar } & \multicolumn{2}{c}{ Hasil Belajar } \\
\cline { 3 - 6 } & & $\begin{array}{c}\text { Equal variances } \\
\text { assumed }\end{array}$ & $\begin{array}{c}\text { Equal variances } \\
\text { not assumed }\end{array}$ & $\begin{array}{c}\text { Equal variances } \\
\text { assumed }\end{array}$ & $\begin{array}{c}\text { Equal variances } \\
\text { not assumed }\end{array}$ \\
\hline Levene's Test for & $\mathrm{F}$ & 0,032 & & 0,917 & \\
Equality of Variances & Sig. & 0,859 & & 0,344 & \\
& $\mathrm{~T}$ & 2,233 & 2,233 & 2,581 & 2,581 \\
& $\mathrm{Df}$ & 40 & 39.740 & 40 & 39.667 \\
\multirow{5}{*}{ t-test $f$} & Sig. (2-tailed) & 0,031 & 0,031 & 0,014 & 0,014 \\
& Mean & 4,095 & 4,095 & 3,000 & 3,000 \\
& Difference & & & & 1,163 \\
& Std. Error & 1,834 & 1,834 & 1,163 & 1,163 \\
& Difference & &
\end{tabular}

(Sumber: Data Primer Terolah 2019)

Berdasarkan hasil analisis deskriptif dari pemberian post-test kuesioner motivasi belajar dan post-test hasil belajar fisika pada kedua kelas yang menjadi sampel penelitian maka diperoleh hasil yaitu (1) deskripsi motivasi belajar peserta didik pada kelas yang diajar menggunakan model pembelajaran learning cycle 5e lebih tinggi dibandingkan dengan kelas yang diajar menggunakan model konvesional hal tersebut terlihat dari pencapaian motivasi belajar kelas eksperimen meliputi rerata skor, standar deviasi dan variansi lebih tinggi dibandingkan dengan pencapaian kelas kontrol hal tersebut terjadi karena sebaran skor motivasi belajar pada kelas eksperimen lebih besar dari pada kelas kontrol, hal ini menunjukan bahwa motivasi belajar peserta didik yang di ajar dengan menggunakan model learning Cycle 5E lebih tinggi daripada motivasi peserta didik yang diajar dengan menggunakan model konvensional.

Hal ini di dukung dengan penelitian yang dilakakukan oleh Ismi yang menyatakan bahwa keterlaksanaan pembelajaran dengan model learning Cycle 5E pada materi gerak harmonik berkategori sangat baik (Candra and Achmadi 2017; Retno Setianingsih 2019). Hal ini juga sejalan dengan penelitian yang dilakukan oleh (Putri Perwita, Rohadi, and Sakti 2019) diperoleh bahwa terdapat pengaruh positif terhadap motivasi belajar peserta didik diterapkannya model learning ceycle 5E di kelas XI SMA; (2) deskripsi hasil belajar fisika peserta didik pada kelas yang diajar menggunakan model pembelajaran learning cycle 5e lebih tinggi dibandingkan dengan kelas yang diajar menggunakan model pembelajaran konvesional hal tersebut terlihat dari pencapaian hasil belajar kelas eksperimen meliputi rerata skor, standar deviasi dan variansi lebih tinggi dibandingkan dengan pencapaian kelas kontrol hal tersebut terjadi karena sebaran skor hasil belajar pada kelas eksperimen lebih besar dari pada kelas kontrol. Hal ini menunjukan bahwa penggunaan model learning cycle 53 dapat meningkatkan hasil belajar fisika. Penelitian ini di dukung oleh penelitian yang dilakukan (Asriyadin et al. 2016). Hasil penelitian menunjukkan bahwa terdapat perbedaan yang signifikan hasil belajar fisika antara yang dibelajarkan dengan model learning cycle 5E dan yang dibelajarkan dengan model konvensional (Direct intruction). Dengan kata lain bahwa model learning cycle 5E lebih unggul dibandingkan dengan model konvensional (Direct intruction) .

Berdasarkan hasil analisis inferensial dari pemberian post-test kuisioner motivasi belajar dan hasil belajar pada kedua kelas yang menjadi sampel penelitian maka diperoleh hasil yaitu (3) terdapat perbedaan motivasi belajar fisika peserta didik yang signifikan antara kelas yang diajar menggunakan model pembelajaran learning cycle 5e dengan kelas yang diajar menggunakan model pembelajaran konvesional. (4) terdapat perbedaan hasil belajar fisika peserta didik yang signifikan antara kelas yang diajar menggunakan model pembelajaran learning cycle 5 e dengan kelas yang diajar menggunakan model pembelajaran konvesional. 


\section{Simpulan}

Berdasarkan hasil analisis dan pembahasan yang diuraikan pada bab sebelumnya, maka dapat disimpulkan bahwa: 1) Deskripsi motivasi belajar fisika menggunakan model pembelajaran learning cycle 5e diperoleh dari nilai rata-rata motivasi belajar fisika siswa sebesar 120,48 pada peserta didik pada kelas XI IPA SMA Negeri 2 Woha Bima; 2) Deskripsi motivasi belajar fisika menggunakan model konvensional diperoleh dari nilai rata-rata motivasi belajar fisika siswa sebesar 116,38 pada peserta didik pada kelas XI IPA SMA Negeri 2 Woha Bima; 3) Deskripsi hasil belajar fisika menggunakan model pembelajaran learning cycle 5E diperoleh dari nilai rata-rata hasil belajar fisika siswa sebesar 21,90 pada peserta didik pada kelas XI IPA SMA Negeri 2 Woha Bima; 4) Deskripsi hasil belajar fisika menggunakan model pembelajaran konvensional diperoleh dari nilai rata-rata hasil belajar fisika siswa sebesar 18,90 pada peserta didik pada kelas XI IPA SMA Negeri 2 Woha Bima; 5) Terdapat perbedaan Motivasi belajar fisika yang signifikan antara yang diajar menggunakan model pembelajaran learning cycle 5E dengan model konvensional peserta didik pada kelas XI IPA SMA Negeri 2 Woha Bima.

\section{Daftar Pustaka}

Aditya, I. Kadek Dwi, Made Sumantri, and I. Gede Astawan. 2019. "Pengaruh Model Pembelajaran Learning Cycle (5E) Berbasis Kearifan Lokal Terhadap Sikap Disiplin Belajar Dan Hasil Belajar Ipa Siswa Kelas Iv Sd Gugus V Kecamatan Sukasada." Jurnal Pendidikan Multikultural Indonesia 2(1):43. doi: 10.23887/jpmu.v2i1.20792.

Asriyadin, Yus'iran, and Hafidah Nurul Fikri. 2016. "Pengaruh Model Learning Cycle 5E Terhadap Hasil Belajar Fisika Siswa Kelas X SMAN 1 Madapangga Tahun Pelajaran 2016/2017.” Jurnal Pendidikan MIPA 6(2):6367.

Candra, Ismy Aulina, and Rasid Achmadi. 2017. "Model Pembelajaran Learning Cycle 7E Untuk Meningkatkan Motivasi Dan Hasil Belajar Siswa Pada Materi Gerak Harmonik Kelas X Di SMAN 1 Kejayan.” Jurnal Inovasi Pendidikan Fisika (JIPF) 06(03):83-90.

Fraenkel, Jack, Norman Wallen, and Helen Hyun. 2011. How to Design and Evaluate Research in Education. Vol. 60.

Hasan, Nurfajri, and B. Nurhayati. 2019. "Pengaruh Model Pembelajaran Learning Cycle 7E Terhadap Minat Dan Hasil Belajar Biologi Peserta Didik Di SMA Negeri 9 Pangkep The Effect of Learning Model 7E Learning Cycle on Interests and Biology Learning Outcomes of Students in SMA 9 Pangkep." Prosiding Seminar Nasioal Biologi VI.

Isnani, Habibah Zilul, Indrawati Indrawati, and Subiki Subiki. 2018. "Model Learning Cycle 5E Dalam Pembelajaran Fluida Dinamis Di Sma (Kajian Pada Keterampilan Proses Sains Dan Hasil Belajar).” Jurnal Pembelajaran Fisika 7(1):38. doi: 10.19184/jpf.v7i1.7223.

Nana Sudjana. 2005. Dasar-Dasar Proses Belajar Mengajar. Bandung: Sinar Baru.

Nisa', Inayatun. 2014. "PENSA E - Jurnal | 26 PENGEMBANGAN PERANGKAT PEMBELAJARAN IPA TERPADU TIPE." Pengembangan Perangkat Pembelajaran Ipa Terpadu Tipe Connected Dengan Topik Peredaran Darah Untuk Kelas Viii Smp 26-38.

Passon, Oliver, Thomas Zügge, and Johannes Grebe-Ellis. 2019. "Pitfalls in the Teaching of Elementary Particle Physics.” Physics Education 54(1). doi: 10.1088/1361-6552/aadbc7.

Putri Perwita, Deby, Nyoman Rohadi, and Dan Indra Sakti. 2019. "Deby Putri Perwita, Nyoman Rohadi, Dan Indra Sakti Hal." Jurnal Kumparan Fisika 2(1):25.

Retno Setianingsih, Suliyanah. 2019. PENERAPAN MODEL LEARNING CYCLE 7E UNTUK MENINGKATKAN LITERASI SAINS PESERTA DIDIK SMA PADA MATERI GERAK HARMONIK SEDERHANA. Vol. 08.

Sari, Yuli Ifana, and Dwi Kurniawati. 2019. "Keterampilan Merancang Lembar Kerja Siswa (LKS) Berbasis Learning Cycle 5E Di MA Khairuddin Gondanglegi." Jurnal Abdimas Berdaya: Jurnal Pembelajaran, Pemberdayaan Dan Pengabdian Masyarakat 2(02):26-35. doi: 10.30736/jab.v2i02.4. 
Senturk, Halil Evren, and Huseyin Camliyer. 2016. "A New Learning Model on Physical Education: 5E Learning Cycle.” Universal Journal of Educational Research 4(1):26-29. doi: 10.13189/ujer.2016.040104.

Sum, Suriya Ningsyih, Syahriani Yulianci, Adi Apriadi Adiansha, Nurjumiati, and Asriyadin. 2020. "Efektifitas Media Pembelajaran IPA Berbasis Masalah Untuk Meningkatkan Kreativitas Mahasiswa Calon Guru SD.” JURNAL PENDIDIKAN MIPA. doi: 10.37630/jpm.v10i1.285.

Suwito, Budijanto, Budi Handoyo, and Singgih Susilo. 2020. "The Effects of 5E Learning Cycle Assisted with Spatial Based Population Geography Textbook on Students' Achievement.” International Journal of Instruction 13(1):315-24. doi: 10.29333/iji.2020.13121a.

Tegeh, I. Made, and Ni Luh Ariesti Pratiwi. 2019. "HUBUNGAN ANTARA MOTIVASI BELAJAR DAN KEAKTIFAN BELAJAR DENGAN HASIL BELAJAR IPA SISWA KELAS V SD.” Jurnal IKA 17(2):15070. 